\title{
Vocational Education and Home-based Work: Socioeconomic Issues of Self-employed Home-based Women Workers in Pakistan
}

\author{
Farhan Navid Yousaf ${ }^{1}$, Muhammad Ashfaq ${ }^{2}$, Akhlaq Ahmad ${ }^{3}$
}

\begin{abstract}
Home-based work is considered a gendered phenomenon as an overwhelming majority of home-based workers comprises women. Despite the fact that millions of women in Pakistan are engaged in home-based work, they are not recognized as workers in national labor laws and are deprived of social protection and other facilities available to workers in formal economy. This research examines socioeconomic problems faced by the women workers, the ways they negotiate those problems, and how vocational education affects their lived experiences. Drawing upon in-depth interviews with home-based women workers in Rawalpindi and Islamabad, the study showed that home-based work is considered appropriate for women because it does not require them to compromise their primary roles as mothers and caregivers for their families. As the home-based work remains un-regularized and outside the radar of labor policies, the women workers faced severe human insecurities, including economic insecurity, shelter insecurity, and health insecurity. Formal vocational training helped the women to enhance their skills according to the market trend and get awareness about the market price of their work.
\end{abstract}

Keywords: Vocational Education, Informal Economy, Self-employed Women, Home-based workers

\section{Introduction}

Home-based work is a gendered phenomenon as an overwhelming majority of home-based workers comprises women. Millions of women in Pakistan are engaged in home-based work however, it remains outside the radar of labor laws, their contribution to national economy is not acknowledged and they are deprived of socioeconomic security as workers. The term home-based workers as defined by the International Labor Organization (2002) according to which home-based workers "refer to the general category of workers who carry out remunerative work within their homes or in the surrounding grounds. It does not refer to either unpaid housework or paid domestic work .refer to either unpaid

\footnotetext{
${ }^{1}$ Assistant Professor, Department of Sociology, IIUI Email: farhan.yousaf@iiu.edu.pk

${ }^{2}$ MS Scholar, Department of Sociology, IIUI Email: ashfaqtakkar@gmail.com

${ }^{3}$ Assistant Professor, Department of Sociology, IIUI Email: akhlaq.ahmad@iiu.edu.pk
} 
housework or paid domestic work. Within the general category of home-based workers, there are two basic types of workers: those who work on their own (the self-employed) and those who work for others (mainly as industrial outworkers).'Informal self-employed workers do not have the protection of social insurance, social security, and old age pension benefits. Informal economic activities include wage workers like informal employees of formal sector and informal employees of informal sector (Chen, 2012). Women in informal economic activities are engaged in jobs that are unstable and lack social and economic security, like cart vending, hawking, roadside cobbling, and domestic work (Avasthy, Ray \& Deb, 2013).

Majority of workers in informal sector do not receive social security and health facilities as their work remains invisible i.e., not covered by labor laws. Further, as the economic contribution of informal sector is not included in the country's gross national product, it remains invisible in the state's economic policies and documents. Some workers may consider informal work more convenient as it does not involve restrictions by employer and the workers have the liberty to start and finish their work according to their own will. However, women workers in informal sector may experience more challenges e.g., obtaining permission of male family members, and taking care of children and other household-related chores along with the work even when they are not feeling well (Olaya, Diaz, \& Caicedo, 2007).

According to Roots for Equity $(2011, \mathrm{p} .14)$, the total work force of home-based women workers (HBWWs) in Pakistan is 12 million. The homebased women's urban workforce comprises $26 \%$ and the rural workforce $74 \%$. Among the four provinces, the urban home-based women workforce in Punjab, Sindh, Baluchistan and Khyber Pakhtunkhwa is $41.9 \%, 24.6 \%, 29.8 \%$ and 3.7\%, respectively.

Shrinking job opportunities in public sector, the number of workers in informal sector, especially of women, has been increasing. However, unfortunately they are not counted in labor force survey because their economic activities are unregistered and unregulated. Pakistan has signed or ratified different international declarations and conventions regarding basic labour rights. However, Pakistani labor laws and Factories Act of 1934 do not consider selfemployed home-based workers as workers because they have no relation with employer and work without any contract due to which they are deprived of their rights of social security, social insurance, and freedom of association. Even labor policies of 1955, 1959, 1969, 1972, 2002, and 2008did not recognize home-based worker as worker because these policies cover only formal economic sectors and enterprises (Raza, 2009). 
In the absence of any regulatory framework, home-based women workers remain vulnerable to abuse and exploitation. Scholars (Khan, 2007; Naseer \& Taib, 2014) note that due to patriarchal structures the majority of home-based women workers are abused physically and verbally. Moreover, home-based women workers face the challenges of non-availability of material resources and frequent electricity load shedding. Social, cultural, and religious barriers in many cases restrict the movement of women and confine them in homes. Due to these various factors, many women prefer to work in their domestic sphere.

\section{Literature Review}

Conditions of home-based women workers vary across countries. For example, in Thailand, Philippines and Indonesia, home-based women workers have easy access to credit, market, and land. Likewise, in Japan home-based women workers are skillfully organized. In India, Self-employed Women Association, in collaboration with different local and international organizations, has been successful in organizing/registering the trade unions of self-employed women workers and raising issues of those women workers (Mehrotra \&Biggeri, 2002). Unfortunately, Pakistan has not yet taken any concrete steps at the national level to organize home-based women workers to protect their rights and to cover them in labor laws. Even those home-based women workers who are able to receive some sort of formal training are generally not aware of the market mechanism and prices of the products they produce; hence they remain vulnerable to socioeconomic exploitation (Oatman, 2007).

The research study of Akhtar and Vanek (2013) reveals that a significant majority of home-based women workers in Pakistanis involved in the manufacturing industry and the number enhanced from 83 percent in 2005-2006 to 91 percent in 2008-2009. Among male home-based workers, ratio in manufacturing industry was 45 percent in 2005-2006 that increased to 54 percent in 2008-2009. Women are dominantly engaged in home-based activities as due to socio-cultural restrictions it becomes very difficult for them to work outside home.

Focusing on the experiences of women workers in informal sector in Delhi, Avasthy et al. (2013) highlighted that the women workers migrated to urban areas due to economic insecurity. The migrated women were dominantly involved in informal activities, like caring children, cleaning clothes, cooking, or worked as vendors. A field research of Hassan (2014), involving interviews with 200 home-based women workers in North, South and Central Punjab, elaborates how home-based women workers face socioeconomic issues. The home-based women workers reported health problems, like joints and muscular pain, eyes 
swelling, headache, backache due to long working hours, unhygienic working conditions, and poor sanitation and sewerage systems.

According to Hassan and Azman (2014), market-based economic inequalities have pushed many women to home-based work or informal economic sector to fulfill the basic needs of their families. Likewise, many women have been restricted to home because their male family members fear that by allowing women to work outside homes, they would not be able to exert patriarchal control over the women. So, they have imposed restrictions on women's work outside homes. Further, the study of Mahadevia, Mishra, and Vyas (2014), conducted on home-based women workers in informal sector in Ahmadabad, India, reveals their socio-economic issues and highlights how particular type of home-based work intersects with religion, caste and other social hierarchies. Women workers were experiencing health issues, like pain in body and eyes.

In Pakistan, Orangi Pilot Project (OPP) has been working in Orangi, Karachi since 1980. Various model programs of OPP have been designed and implemented focusing on women's issues, for example, family planning, immunization, and women involved in informal economic sector. The handicrafts prepared by the women are exported to international market, including America and Europe (Khan, 1992).According to Kabeer (2012), inclusive employment helps economic empowerment of women. Focusing on the education of both men and women can provide them equal economic opportunities and address gender inequalities. However, prevailing labor market conditions clearly exhibit different gender-related inequalities restricting the choices available to women.

The above brief review of literature indicates that informal workers, particularly home-based women workers, remain invisible part of economy; therefore, policy interventions are needed not only to acknowledge the contribution of home-based workers to the national economy but also to address the problems they face in their everyday lives. This study adds to the existing knowledge on home-based women workers by examining how the women negotiate socioeconomic and cultural barriers or challenges. Moreover, by comparing the working experiences of home-based women workers who received formal training with those who did not receive any formal training, the study sheds light on how formal training affect the experiences of home-based women workers. 


\subsection{Research Design}

\section{Research Methodology}

Present research has undertaken interpretive epistemological stance and used qualitative research design.

\subsection{Population and Sample}

Data were collected from self-employed home-based women workers in two localities: Dhoke Hassu in Rawalpindi and Christian Colony in Islamabad. The particular research sites were selected after consultation and meetings with several organizations that were providing vocational education/training to homebased women workers and/or working on addressing issues faced by the women workers. After the meetings two research sites were identified/selected because of the concentration of home-based women workers engaged in sewing/stitching clothes and embroidery work. The majority of home-based women workers in "Dhoke Hassu" had received or was receiving formal education/training in different private vocational training centers. However, home-based women workers in "Christian Colony" had not received any formal education/ training. Hence the selection of the two sites enabled to examine how vocational education/training affects the experiences of home-based-women workers.

\subsection{Sampling Technique}

Out of total 20 respondents, 10 respondents were selected from each locality. As mentioned before, the women workers in Dhoke Hassu had received formal training in sewing/stitching and embroidery while in Christian Colony the women workers did not receive any formal training. To select both categories of the respondents, snowball sampling technique was used. Initially few women respondents were contacted with the help of the organizations working on the issues of home-based women workers. From these initial contacts, snowball sample was built.

\subsection{Research Instrument}

A checklist was used to document the socio-demographic characteristics of the respondents. In total, 20 in-depth interviews from self-employed homebased women workers were conducted.

\subsection{Data Analysis}

Thematic analysis was used to identify different patterns or themes in the data. According to Clarke and Braun (2013), the technique of thematic analysis can be used to analyze primary data e.g. interview transcripts and secondary data e.g. data obtained from archival sources. Thematic analysis comprises several steps or stages whereby every step contributes to the understanding of the issue and addressing the research objectives. The analysis starts with a careful and 
systematic reading of data and developing codes. The codes help to identify main themes in the data and understand relationship between different themes or dimensions of the data enabling the researchers to make arguments and draw conclusion grounded in the data. Keeping in view the ethical issues involved in social research, the study was guided by the standards of ethics followed in social sciences.

\subsection{Work Choice}

\section{Results and Discussion}

Home-based women workers from both the locales revealed that sewing clothes and embroidery were their work choice because they could do these works within their homes without confronting male family members who did not want them or allowed them to work outside their homes. Many home-based women workers wanted to engage in sewing clothes or embroidery to earn income because they had seen other female family members doing these works and learnt these skills from them in their homes. A young home-based worker explained:

"Family environment, restrictions and insufficient family income were the main motivating factors to choose sewing clothes as home-based work. Moreover, many of my other female family members were involved in sewing and embroidery work and doing work inside home was the first priority of my family".

In addition, for many home-based women workers sewing clothes and embroidery were the only options of work available to them as it was easy for them to learn these skills and did not require huge economic resources. Likewise, they were of the view that as they had no or less information about other jobs and lack education, hence, they would not be able to get jobs offered by different organizations. As the women had been sewing clothes for their brothers, sisters, and other family members, they perceived this work more convenient for them.

\subsection{Economic Insecurity}

Home-based women workers who received formal training and those who did not receive any formal training both faced economic insecurity in their lives as they did not have enough income to fulfill their basic needs. Some homebased women workers emphasized that due to unemployed husbands, they started working as home-based workers to meet some basic family needs like seeking medical treatment during illness and paying children's school fees. Home-based women workers from both locales emphasized that economic insecurity was a major problem associated with their work that had psychologically, physically, 
socially and economically ruined their lives. Many of the poor women workers had no alternative source of income and relied on their husbands' or other male members' earnings. One of the respondents stated:

"We do not have any opportunity to earn income except from sewing clothes or to rely on husband and family members' income. But our family income is not enough even to meet our daily basic needs which cause a continuous mental stress for us".

In order to overcome the economic insecurity, many women started working as home-based workers and preferred sewing clothes or/and embroidery work as it was considered the easiest source of income for those women who cannot work outside home and do not require intensive technical skills. Many respondents shared that they were neither aware of any kind of bank loan financing opportunities nor had they any information how to get loan from banks in order start personal business.

In the absence of any formal support systems, during times of crisis, home-based women workers provide informal support to each other. However, illness, many of them relied on other home-based workers in their neighbors to complete their orders till the time they recovered from illness.

Many women workers had to do work for more than 12 hours a day, in addition to performing their regular household chores, which negatively affected their physical health. The situation was even worse for those women workers who were the heads of their families because of the death of their parents or husbands and were solely responsible to manage the expenditure of their families. A 19-years old home-based woman worker told:

"After the death of my parents, being the eldest family member, I had to take care of my younger siblings. I started working as home-based worker to earn money and to fulfill the needs of my two younger sisters and one brother who are getting education in school. I stay at home and stitch clothes and embroidery work to pay school fees of my younger siblings and take care of other family needs like food. But still the income that I earn from my work is not enough".

\subsection{Facets of Patriarchy and Home-based Work of Women}

The home-based women workers at Dhoke Hassu in Rawalpindi, shared it was mandatory for them to seek prior approval of their male family members, including husband, father, and brothers who had the decision-making power. The women workers could not work or express their desire to work outside their homes because they had fear of their husbands or other family members who 
considered outside working of women as social evil and violation of their norms and values that could bring shame or dishonor to the family.

Social pressure always exists in the mind of home-based women workers that they cannot violate the stringent family norms. It was very challenging for the women workers to attend sewing centers to learn or polish their skills, but they were able to seek permission from male family members.

Male family members would buy the raw material for the women or they would go with them to the market. A 30-year-old woman who was receiving training in a vocational training centre said:

"My family never really considered my receiving training in

the training centre as an appropriate act because they still think it is against their values and according to them any outside home engagement of a woman devalues her personal respect. In our society, it is believed that a woman is born only to pay attention to household-related activities and take care of her family members instead of going and doing work outside home".

The above quotation clearly marks the rigid norms that restrict the social mobility of home-based women workers. As Hassan \& Azman (2014) have argued that family honor is associated with women, they are socially isolated and confined to home-based work that yields less economic recognition and reward.

The situation or living experiences of self-employed home-based women workers in Christian Colony were not the same. The home-based women workers in this locality shared that they could either go to the market for buying raw material with their male family members or alone as their movement was not restricted by their husband/father/brothers.

Comparing the experiences of self-employed home-based workers in two different locales, we can clearly identify how cultural norms intersect with patriarchy. In Dhoke Hassu, Rawalpindi, women were not allowed to work outside home. On the other hand, the women workers in Christian Colony could not receive any vocational training but they perceived that doing home-based work was their own choice as they did not have any social pressure or restriction to engage in outside home economic activities.

\subsection{Challenges faced by Self-employed Home-based Women Workers}

Many home-based women workers faced restrictions for engagement in outside home activities and could not spend more time in training centers because of the fear of their (male) family members. In such situation, not surprisingly, 
getting family permission to attend the vocational training centre was a real challenge for the women. To negotiate this challenge, the women workers would seek permission from family to attend the vocational training centre by referring to other women among their relatives or neighborhood who were already receiving the training and contributing to family income.

Attending vocational training centre did not mean that the women were relieved from their traditional household responsibilities. The women were well aware that although they got permission to attend vocational training classes, they could not provide any reason to the family members to revisit their permission by neglecting their household chores - their primary gender roles. Hence, the women would invest extra time and energy to complete their usual household tasks before going to the vocational training centre. But for them this was the only workable option in order to attend the vocational training classes. One of the respondents shared her experiences which are as follows:-

"It is very difficult for us to go to sewing centre and leave our babies at home or at relatives' homes for short time. We particularly face problems from our husbands because they do not like this arrangement to go to the sewing centre. We are aware that our husbands want us to remain at home and do household work. Therefore, we invest more time to fulfill the domestic responsibilities and only after finishing the household work we leave for sewing centre".

Moreover, the women workers had to face many problems on their way to training centers. Many respondents shared that access to public transport was a major issue for them to commute to the training centre. In addition, the women workers told that they would frequently experience harassment, staring, and/or unwanted comments from males while commuting to the training centers. The women would ignore these acts and prefer not to inform their male family members about this issue because they knew it that if they informed male family members then they would not allow them to go outside home.

On the other hand, the home-based women workers in Christian Colony, who did not receive any formal training, told that they did not face such problems outside their homes. They could easily go to the nearby market without any fear of harassment and their husbands supported them to engage in home-based work. One of the main reasons that the women could easily move in Christian Colony was that the people living in the colony were strongly integrated and personally knew each other. One of the respondents said: 
"We do not feel any fear while going out in Christian Colony. Neither do our male family members restrict us to remain inside homes. In our own area mostly people have good relations with each other and due to that reason every person respects each other, especially women".

However, the home-based women workers in Christian Colony faced many other problems. For example, many of them shared that they wanted their children to acquire higher education to earn better future for themselves and their families, but as their work did not yield enough money it was really challenging for them to pursue their goal.

Another major problem faced by the women workers in this community was the shelter insecurity. As they did not own the land and their houses were built on the government land, they were highly insecure about their residency. They informed that sometimes police and government officials would come and ask them to vacate the place stating that they were living there illegally. One of the respondents revealed:

"I have constant fear of police because they threaten us frequently to leave this place and go somewhere else. Sometimes I am so afraid and depressed that I cannot perform work order".

Frequent and extended electricity load shedding was also a major issue of the home-based women workers. The women workers shared that sometimes they had electricity only for 7 to 8 hours in a day due to which they found it really hard to complete their work orders in time and provide justification to the customer about the delay.

The home-based women workers in Christian Colony who did not receive any formal training also reported that they did not have advance sewing machines and sewing/embroidery skills. The simple sewing/embroidery skills they had were becoming outdated for the clients. They said that many customers demand new or latest designs in dresses while others still rely on old simple designs. As the women workers were designing and sewing old traditional dresses, many customers ordered their dresses in the market where they were not only able to receive their stitched clothes back in time as the tailors could afford generator facility but also they could select new dress designs. Because of these reasons, many customers then did not order clothes to the home-based women workers.

Health is also a cross cutting issue in the lives of home-based women workers. As they were living in impoverished areas and conditions where health facilities were not adequately available or even if health facilities were available 
they did not have enough resources to afford those facilities. During interviews with the women workers, the majority of them reported various health issues they were suffering from, for example, continuous headache, weak eyesight, swollen eyes, backache, swollen feet, mainly due to unhygienic working/living conditions, long working hours and poor sanitation and sewerage system.

\subsection{Effects of Vocational Training}

Those home-based women workers who received formal vocational training emphasized that they knew very little about sewing clothes and embroidery until they joined vocational training centre. After joining the training centre, their skills were greatly improved, and they learnt new designing and sewing techniques. One respondent explained:-

"Now I can realize that before joining the vocational training center, I significantly lacked skills in embroidery and stitching clothes. But when I joined the sewing center then I got this opportunity to learn more advance techniques under the guidance of a qualified instructor".

Home-based women workers indicated that initially they did not have any information about the vocational training centers run by the government and non-governmental organizations and their different programs or courses offered for the women. They came to know about the centers from their relatives or neighbors. After joining the centre, they realized that getting training was not difficult rather they found it interesting to learn new skills under guidance of qualified instructors. At the end of each class, they were assigned daily homebased practice tasks.

The women workers shared that after attending the vocational training centre they gained confidence and updated skills to produce new clothing designs which increased their demand and productivity. They revealed that they were not much familiar with market rates for stitching and embroidery, but after that they got some idea about the worth of their skills and the market rates which helped them to better negotiate with the clients. They also got more information about the quality and types of raw material. Due to enhanced skills and improved productivity, women also realized them that they were no more economically dependent as they were now contributing in family income. But after acquiring the advanced skills, they realized that through their work they could earn money for themselves and their families. One respondent said:

"Before joining the vocational training centre, I was not aware of the market price of the work I performed and did not know how to deal with the clients. But after joining the sewing center, I came to know about market situation. 
Learning new skills at the centre made me more confident about my work and provided the opportunity to become an earning member of the family".

However, these home-based women workers could not go to market for selling their own stitched clothes or take direct orders from the market because it was considered as violation of their family norms and values. The majority of the workers shared that before attending the sewing centre they used to give their own fancy clothes to tailors in market on special occasions and had to pay them high amounts. While attending the vocational training centers, the home-based women workers also learnt about the maintenance of their sewing machines and repairing some basic disorders of the machines that again helped them to save some time and money involved in the repair of machines from the market.

\section{Conclusion}

The study reveals that due to socio-cultural barriers and gendered socialization home-based work is considered appropriate for women as they do not have to compromise their primary roles as mothers and caregivers for their families. Economic insecurity, shelter insecurity, and health insecurity were the main issues confronted by all the home-based women workers. Home-based women workers who received formal training, getting permission from family were a major challenge. But they negotiated that by referring to or getting support from other women among their relatives or neighborhood who were already receiving the training and contributing to family income and by not sharing the problems they faced, e.g. harassment, while commuting to the centers. Conversely, in Christian Colony, though the women did not feel family pressure to remain inside home, they could not get vocational training because of lack of access to vocational training centre. The women workers who received formal training were able to enhance their sewing and embroidery skills, get awareness about market prices and rights as workers, and acquire some basic skills in repairing their sewing/embroidery machines. They were relatively earning higher than those home-based women workers who could not receive any training.

\section{Recommendation}

The government, in collaboration with other stakeholders, should recognize home-based workers as workers in labor laws and design interventions to address their issues and protect their rights as per international labor standards. 


\section{References}

Akhtar, S., \& Vanek, J. (2013). Home-based workers in Pakistan: Statistics and trends. Women in Informal Employment, Globalizing and Organizing, 9, $1-7$.

Avasthy, D., Ray, A. K., \& Deb, R. (2013). Women informal economy: Its characteristics and legitimacy in the intergenerational context. Cuadernosrnos Hispanoamericnosde Psicología, 13(1), 4-12.

Chen, M. A. (2012). The informal economy: Definitions, theories and policies. WIEGO working paper No. 1. Cambridge, MA: Women in Informal Employment, Globalizing and Organizing.

Clarke, V., \& Braun, V. (2013). Teaching thematic analysis: Overcoming challenges and developing strategies for effective learning. The Psychologist, 26(2), 120-123.

Hassan, S. M. (2014). Need assessment of home based women workers: A new paradigm for social work. Science International, 26(3), 1253-58.

Hassan, S. M., \& Azman, A. (2014). Visible work, invisible workers: A study of women home based workers in Pakistan. International Journal of Social Work and Human Services Practice, 2(2), 48-55.

International Labor Organization. (2002). Men in the informal economy: A statistical picture. Geneva: International Labor Organization.

Kabeer, N. (2012). Women's economic empowerment and inclusive growth: Labour markets and enterprise development. SIG Working Paper 2012/1. Retrieved from https://www.idrc.ca/sites/default/files/sp/Documents\%20EN/NK-WEEConcept-Paper.pdf

Khan, A. (2007).Women and paid work in Pakistan: Pathways of women's empowerment, South Asia research program, Pakistan scoping paper. Karachi, Pakistan: Collective for Social Science Research.

Khan, A. H. (1992). Orangi pilot project programs (2 ${ }^{\text {nd }}$ ed.). Karachi, Pakistan: Orangi Pilot Project Research \& Training Institute.

Mahadevia, D., Mishra, A., \& Vyas, S. (2014). Informal economy monitoring study: Home-based workers in Ahmedabad, India. Cambridge, MA: Women in Informal Employment: Globalizing and Organizing. 
Mehrotra, S. \& Biggeri, M. (2002). Social protection in the informal economy: Homebased women workers and outsourced manufacturing in Asia. Innocenti Working Paper No. 97. Florence: UNICEF, Innocenti Research Centre.

Naseer, M. \&Taib, A. (2014). Psycho-social problems of female entrepreneur in Pakistan: An analysis. Journal of Professional Research in Social Sciences, 1(1), 1-9.

Oatman, M. S. (2007). Self-employed, self-empowered: Working women in Benares.

Retrieved fromhttp://digitalcollections.sit.edu/cgi/viewcontent.cgi?article $=1210 \& \mathrm{c}$ ontext=isp_collection

Olaya, C., Diaz, F. A., \&Caicedo, S. (2007). Towards a system dynamics model of De Soto's theory on informal economy. Retrieved from https://papers.ssrn.com/sol3/papers.cfm?abstract_id=2764107

Raza, M. K. (2009). Invisible workers: Case of home-based women workers in Pakistan. Retrieved from http://lup.lub.lu.se/luur/download?func $=$ downloadFile\&recordOId $=1734$ $847 \&$ fileOId $=1734852$

Roots for Equity. (2011). Unacknowledged treasures: The home-based women labor of Pakistan. Retrieved from https://rootsforequity.noblogs.org/files/2014/09/UnacknowledgedTreasure.pdf 